\title{
Susceptibility of Sensor Networks to Intentional Electromagnetic Interference
}

\author{
J. Delsing ${ }^{1}$, J. Ekman ${ }^{1}$, J. Johansson ${ }^{1}$, \\ S. Sundberg ${ }^{1}$, M. Bäckström ${ }^{2}$, T. Nilsson ${ }^{2}$ \\ ${ }^{1}$ EISLAB, Luleå University of Technology, Sweden \\ ${ }^{2}$ Swedish Defence Research Agency FOI, Division of Sensor Technology
}

\begin{abstract}
It is reasonable to think that sensor networks might be part of society critical systems in the future. Therefor this paper discusses and shows the vulnerabilities of sensor networks to intentional electromagnetic interference (IEMI). Principle ways of sensor network IEMI is addressed and followed by a discussion on schemes for protection. Experimental results for both in-band and exband interference from low- and high- level sources is reported. It is obvious that more emphasis has to be put on sensor networks susceptibility to IEMI, and in particular more experimental data is needed.
\end{abstract}

\section{INTRODUCTION}

Sensor networks is one of the most rapidly expanding research areas within information technology today. For reviews of current sensor network research see for example [1], [2]. Today we find potential applications for sensor network technology almost everywhere in our society. For example within sports, medicine, process industry, agriculture, energy generation etc. Therefore, sensor networks might be part of society critical systems in the future. Keeping this in mind, it is of clear interest to discuss and report the potential threats of IEMI on sensor networks. Although sensor networks being in an early stage of development, the introduction of IEMI discussion possibly can reduce future problems.

Intentional EMI can be generated in several ways [3], [4] depending on the purpose and the distance of action. There exist military high-power microwave (HPM) sources with output powers of up to tens of gigawatts, HPM sources for operation using vans $(\sim \mathrm{MW})$, and pocket size devices $(\sim \mathrm{kW})$. The disturbing electromagnetic energy will be of high energy, narrow/wideband possibly targeting popular communication frequency bands, and intermittent in time. Some details on IEMI susceptibility to HPM can be found in [5].

Since it is obvious that sensor networks will be threatened by IEMI, this paper discusses different possibilities of IEMI to sensor networks, measures to reduce or avoid the effects, and report experimental results from IEMI sensor network testing.

\section{SENSOR NETWORKS}

Sensor networks are still rather undefined. In general they are formed by sensors nodes with one sensor/actuator, computing and communication capabilities. The sensor nodes will ad-hoc form a network capable of connecting every sensor to the Internet via access points. This network topology is described in Fig. 1 with

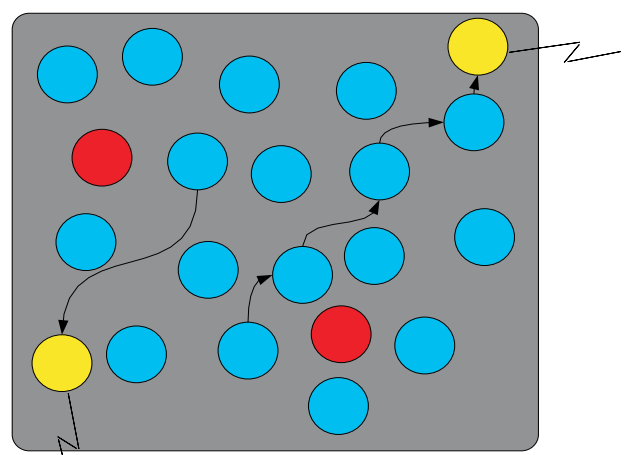

Fig. 1. Sensor network topology with multiple access points (yellow) allowing both point-to-point and multi-hop communication. IEMI sources, in red, can impair both access points and sensor nodes.

sensor nodes (blue) and multiple access points (yellow) and the potential IEMI sources (red) located locally within the sensor network. Most sensor networks are given the following characteristics;

- ad-hoc networking capabilities,

- physically small devices $\left(\mathrm{cm}^{3}\right.$ down to $\left.\mathrm{mm}^{3}\right)$,

- wireless communication,

- from 2 to very large numbers of nodes,

- power supply is very limited,

- distance between sensor nodes are most often in the order of hundreds of meters or less,

- communication topologies can be both point-to-point and multi hop with routing capabilities,

- connection to the Internet via access point.

Sensor network node designs found in the literature are the Berkeley MOTE [6], BTNode from ETH Zurich [7], iBadge from UCLA [8], and MANTIS from Univ. of Colorado [9]. Commercially available sensor network node are for example the Crossbow MOTE [10]. The sensor nodes considered in this paper is one of the most advanced sensor network node available named MULLE [11] which is further described in Sec. II-A. The discussion will be general as most today know sensor network architectures and node designs.

\section{A. Example Ad-Hoc Sensor Network Node}

MULLE is an example of a minimal ad-hoc sensor network node designed at EISLAB, Luleå University of Technology, Sweden [11]. In the procedure to create the MULLE requirements, effort was put to use solutions that were actually realizable or already in use. For example 
a fully integrated web server, wireless communication, time stamping in real time, minimal system size $(25 \mathrm{x}$ $25 \times 5 \mathrm{~mm}$ ), extremely low and flexible power supplies and power down mode, analog and digital I/O, and power supply output to provide power for externally connected sensors. For the discussion, MULLE is equipped with a standard PT-100 temperature sensor.

The wireless communication of the MULLE is a WMLC10AHR Bluetooth [12] module with integrated antenna from Mitsumi [13]. The working range frequency of the Bluetooth module is from 2.402 to $2.480 \mathrm{GHz}$.

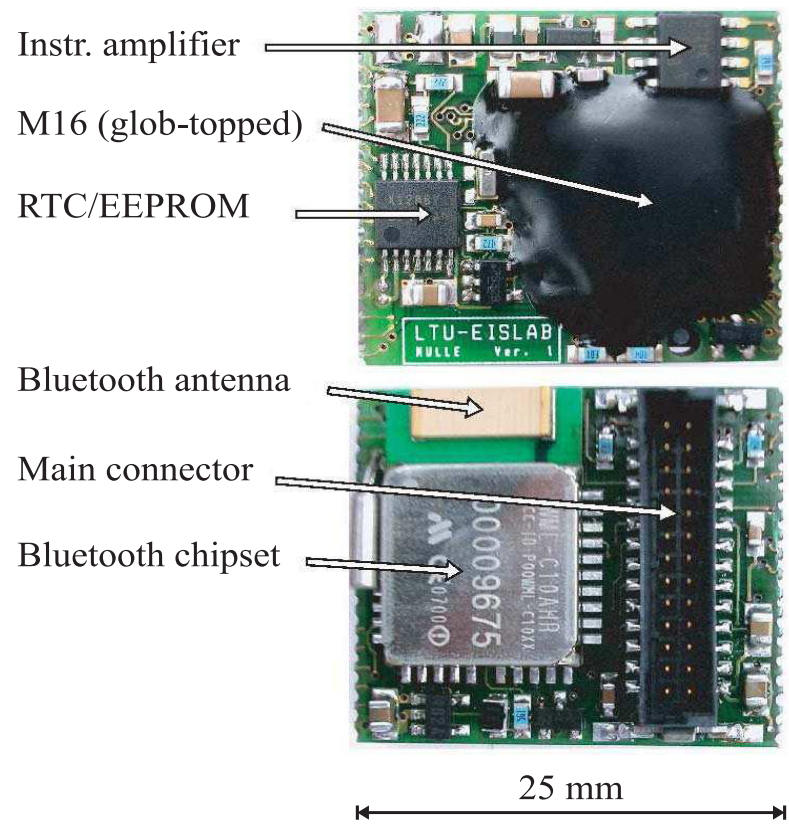

Fig. 2. Photo of example ad-hoc sensor network node (MULLE) with dimensions and indications of main components.

\section{IEMI FOR AD-HOC SENSOR NETWORKS}

A sensor network functionality susceptibility to IEMI can be characterized in the following general ways:

- IEMI that impair via the sensor interface on the physical function (front door coupling),

- IEMI that impair the sensor node functionality (back door coupling),

- IEMI that impair the communication between with sensor nodes (front door coupling and false information)

The susceptibility can cause upset, permanent failure, or permanent damage. From Bäckström [5] we find that for systems like standard computers back door and out-ofband front door upsets typically occur from field strengths of around $200 \mathrm{~V} / \mathrm{m}$. Permanent damage may occur at field strengths from a couple of $\mathrm{kV} / \mathrm{m}$ and higher.

The general issues for IEMI for sensor networks is that the dimensions of the sensor nodes are expected to shrink to a few $\mathrm{cm}^{3}$ and potentially to $\mathrm{mm}^{3}$. This limited size reduces the EMI protection possibilities. The size does on the other hand indicate that higher frequencies are needed for harmful EMI. Another issue is that IEMI (can) have considerably stronger fields than current testing standards are devised for. This will impose new design problems for the sensor interface.

The wireless communication of the sensor network provides the last general way of susceptibility. This type of IEMI can be issued as a way of distribute false information in the network or to cause denial of service where no information is distributed. This is similar to a electronic warfare situation.

There are currently several technology developments having interesting features considering mitigation of IEMI for sensor networks. Encapsulation material feasible for minimal devices are of interest. Here laminate material like ProofCap [14] is of particular interest. It will both give protection for EMI and enable the integration of communication antennas [15] see Fig. 3. The design technology opens up a frequency selective channel into the electronics of the sensor node, thus minimizing back door susceptibility. For some types of sensor interfaces, such laminate material can provide a feasible sensor interface for front door EMI protection. Since most IEMI

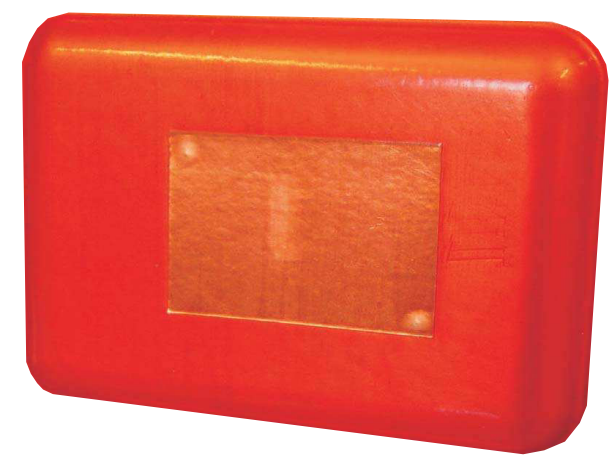

Fig. 3. Laminated encapsulation materials with integrated antennas enabling a frequency selective channel to the encapsulated device.

is expected to be both localized and intermittent one way of reducing IEMI upset is by reducing the probability of interference. Interesting approaches for handling this is:

- sensor node redundancy,

- internet like sensor network communication,

- reactive time synchronized sensor network architecture.

With the assumption that IEMI very often is local i.e. disturbance within a couple of meters it will become obvious that some of the functionality can be preserved with duplication of nodes at some distance. This will open the possibility for communications schemes that adapts to the new conditions in the network and enables information to be sent through other nodes than the upset ones.

Another approach is sensor network nodes working in a totally reactive way, so that communication only occur when a system need is present. This will give very sparse communication and therefore limit the possibilities of IEMI from localized and intermittent sources. 


\section{EMI TESTS OF SENSOR Network Node}

\section{A. Initial Testing}

We have made a few in-house radiated immunity tests of a sensor network of two bare MULLE devices, Fig. 2, measuring temperature in a Bluetooth pico net configuration with an iPaq as access point. The tests were performed for $80-1000 \mathrm{MHz} \mathrm{CW}$, vertical and horizontal polarization, and field strengths of $10-20 \mathrm{~V} / \mathrm{m}$ in an full anechoic chamber. Standard EMC testing signal generation and amplification was used in conjunction with a BiLog antenna to generate the interfering fields. The sensors were requested to measure temperature every 2 seconds and data was transmitted from the on board web servers to a browser at the iPaq which was observed through a video link into the chamber. No IEMI effects were detected, i.e. no data impairment, nor any communication impairment. This was expected since the frequency used was too low to affect the $2.5 \mathrm{GHz}$ Bluetooth communication. Based on the device size frequencies of up to several of $\mathrm{GHz}$ would presumably be required to open a threat to the sensor or the sensor network node itself.

\section{B. High-level Testing}

Additional high level testing has been done at the HPM lab at the Swedish Defense Research Agency FOI in Linköping, Sweden. The MULLE device was set up in a similar way as the initial testing.

1) Test setup: A schematic picture of the test setup is seen in Fig. 4. The antenna is a A6100 dual polarized circular horn antenna. The access point for the MULLE device was a laptop shoving the current temperature and

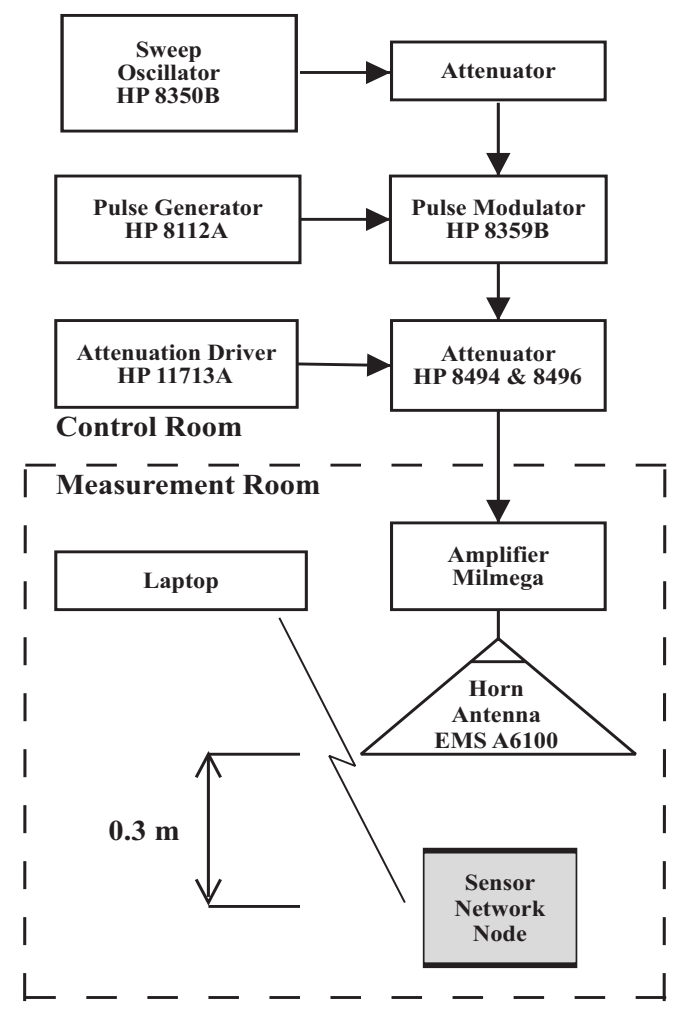

Fig. 4. The experimental setup. a graph over the temperature for the past minutes. The sensor was requested to measure temperature every five seconds and update the graph. The laptop was placed inside the screened room, protected from the radiation, and observed through a shielded video link into the room.

For every frequency and radiation level the device was exposed 60 seconds. For the frequencies that proved to be more interesting, testing with an additional 180 seconds was done to find a more accurate radiation level where the interference starts.

Losses in cables and connections have been measured and corrected for. The gain of the horn antenna varies with the frequency $(2.0$ to $3.0 \mathrm{GHz})$ and the value is rounded before computing the field strengths. The input power to the antenna has an uncertainty of about $\pm 0.1 \mathrm{~dB}$ and the uncertainty in the calculated field strengths, Table I, is estimated to less than $\pm 0.5 \mathrm{~dB}$.

2) Continuous wave and pulsed test: The continuous wave $(\mathrm{CW})$ and the pulsed tests were done in the test setup described above and Fig. 4. Table I shows the maximum radiation levels for the tests. The pulses were at $1 \mathrm{kHz}$ with a pulse length of $100 \mathrm{~ns}$ and a period of $1 \mathrm{~ms}$. The pulsed test gave no visible results and this is believed to be due to the relatively low radiated (average) power. In the CW tests the MULLE device was shown to be sensitive to the frequencies $2.25 \mathrm{GHz}$ and $2.45 \mathrm{GHz}$.

At $2.25 \mathrm{GHz}$ the temperature sensor was affected, yielding a temperature rise visible in the graph. At the highest levels in the other frequencies some temperature difference could be seen, but the difference was so small that the results was inconclusive. This could be due to the sensor warming up from the radiation and/or from immunity problems in the few $\mathrm{cm}$ of cable from the sensor to the MULLE-device.

At $2.45 \mathrm{GHz}$ the communication was disturbed. This was expected since the Bluetooth communications is within 2.4-2.5 GHz. This was tested at two occasions. The first occasion was late in the day when the sensor had been exposed to significant radiation for most of the day. At this occasion the communication was disturbed so badly that the connection was lost. When the connection was resumed at the access point the MULLE device was sending double data. When the MULLE was reset it started to work in a normal manner again. The second test occasion was when the system had been shut off over the night and this was the first test of that day. Then the only visible results were loss of data, but the communication between the sensor and the access point still remained intact.

The major effects from the high-level tests are summarized in Table II.

3) Microwave oven test: The last test done was with a manually modified microwave oven seen in Fig. 5. This test was mainly to see what effect an improvised EMI device could have. The working frequency of the microwave oven is at $2.47 \mathrm{GHz}$ and it has a max power of $900 \mathrm{~W}$. The microwave oven has a duty cycle of about $50 \%$ and a pulse length of $20 \mathrm{~s}$. The generated pulsed field that the MULLE was exposed to was about $600 \mathrm{~V} / \mathrm{m}$.

This device did not disturb the communication between the MULLE and the access point. It did however affect 
TABLE I

CALCULATED ELECTRIC FIELD LEVELS (MAXIMUM) FOR HIGH-LEVEL TESTING.

\begin{tabular}{c|c} 
Frequency $[\mathrm{GHz}]$ & Max. E-field level $[\mathrm{kV} / \mathrm{m}]$ \\
\hline \hline 2.00 & 0.29 \\
\hline 2.25 & 0.29 \\
\hline 2.45 & 0.25 \\
\hline 2.50 & 0.24 \\
\hline 2.75 & 0.34 \\
\hline 3.00 & 0.36
\end{tabular}

TABLE II

SUMMARY OF IEMI INDUCED EFFECTS FOR THE SENSOR NETWORK.

\begin{tabular}{c|c|l} 
Frequency $[\mathrm{GHz}]$ & E-field level $[\mathrm{kV} / \mathrm{m}]$ & Comment \\
\hline \hline 2.25 & 0.13 & Visible temperature rise. \\
\hline & 0.29 & $\begin{array}{l}\text { Max level: } \sim 7^{\circ} \mathrm{C} \\
\text { temperature rise. }\end{array}$ \\
\hline 2.45 & 0.20 & First visible data loss. \\
\hline & 0.22 & $\begin{array}{l}\text { Loss of contact at one } \\
\text { test occasion. }\end{array}$ \\
\hline 2.47 & 0.25 & Max level: visible data loss \\
\hline & 0.60 & $\begin{array}{l}\text { Microwave oven test: } \sim 20^{\circ} \mathrm{C} \\
\text { temperature rise. }\end{array}$
\end{tabular}

the temperature sensor so that a temperature rise of at most $20^{\circ} \mathrm{C}$ could be seen. The pulsed radiated EM field from the microwave oven configuration could be clearly seen in the temperature graph.

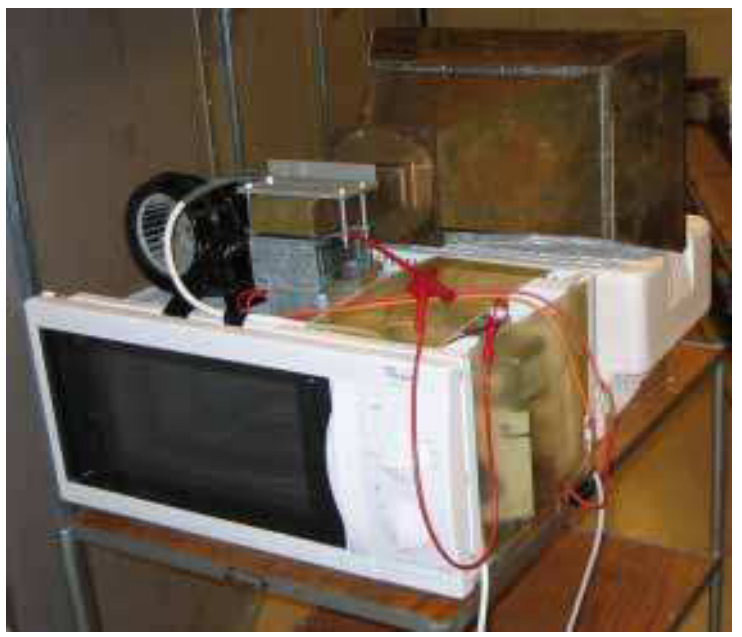

Fig. 5. The modified microwave oven.

4) Summary of high level testing: The tests shows that the communication scheme of the MULLE device is very robust and that the most susceptible part of MULLE is the temperature sensor.

The main advantages of the MULLE is its size, which limits the lowest frequencies that could possibly interfere with the device, and the communication using the Bluetooth protocol.

The Bluetooth protocol is designed to avoid interfer- ence by a frequency hopping scheme which operates over 79 channels of $1 \mathrm{MHz}$ each. The frequency hopping is done in a pseudo-random manner about 1600 times per second. This means that if one channel is disturbed by a narrow-band source, this will have little effect on the overall communication since there are still 78 channels left to use.

\section{CONCLUSION}

The work presented here shows that there is a need for additional sensor network research which can put more focus on improving the immunity of sensor networks to IEMI. Results from the high-level testing show that sensor networks can be hampered by IEMI. In this article we report data loss, loss of contact, and impact on sensor functionality for an unshielded sensor network based on the network node entitled MULLE. Further, it is clear that current research in sensor networks does not consider IEMI as a serious threat. In particularly it is clear that more experimental data is needed, especially regarding susceptibility to wide-band pulses, thus enabling a better understanding of the susceptibility of sensor networks.

\section{REFERENCES}

[1] J. Delsing and P. Lindgren, "Sensor communication technology towards ambient intelligence, a review," Meas. Sci. Technol., vol. 16 , pp. 37-46, 2005.

[2] V. Raghunatahan, C. Schugers, S. Park, and M. B. Srivastava, "Energy aware wireless microsensor networks," IEEE Signal Processing Mag., pp. 40-50, March 2002.

[3] D. V. Giri and F. M. Tesche, "Classification of intentional electromagnetic environments (IEME)," IEEE Trans. Electromagn. Compat., vol. 46, no. 3, pp. 322-328, 2004.

[4] D. Giri, "High-power electromagnetic (HPEM) radiators and intentional electromagnetic interference (IEMI), in Proc. of RVK, Sweden, 2005, pp. 7-13.

[5] M. G. Bäckström and K. G. Lövstrand, "Susceptibility of electronic systems to high-power microwaves: Summary of test experience," IEEE Trans. Electromagn. Compat., vol. 46, no. 3, 2004.

[6] B. Warneke, B. Atwood, and K. Pister, "Smart dust mote forerunners," in Proc. of the 14th IEEE Int. Conf. on Micro Electro Mechanical Systems (MEMS), 2001, pp. 357-360.

[7] J. Beutel, O. Kasten, F. Mattern, K. Roemer, F. Siegemund, and L. Thiele, "Prototyping wireless sensor network applications with BTnodes," in Proc. of 1st IEEE European Workshop on Wireless Sensor Networks (EWSN), Berlin, Jan. 2004.

[8] M. Srivastava, R. Muntz, and M. Potkonjak, "Smart kindergarten: Sensorbased wireless networks for smart developmental problemsolving environments," in Proc. of the ACM SIGMOBILE 7th Annual Int. Conf. on Mobile Computing and Networking, Rome, July 2001.

[9] H. Abrach, S. Bhatti, J. Carlson, H. Dai, J. Rose, A. Sheth, B. Shucker, J. Deng, and R. Han, "MANTIS: System Support For MultimodAl NeTworks of In-situ Sensors," in Proc. 2nd ACM Int. Workshop on Wireless Sensor Networks and Applications (WSNA), 2003, pp. 50-59.

[10] (2005) Crossbow Inc. home page. [Online]. Available: http: //www.crossbow.com

[11] J. Johansson, M. Völker, J. Eliasson, Å. Östmark, P. Lindgren, and J. Delsing, "MULLE:a minimal sensor networking device implementation and manufacturing challenges," in Proc. IMAPS Nordic, Sept. 2004, pp. 265-271.

[12] (2005) Bluetooth. home page. [Online]. Available: http://www. bluetooth.org

[13] (2005) Mitsumi electronics Corp. home page. [Online]. Available: http://www.mitsumi.com/indexusa.html/

[14] (2005) ProofCap AB home page. [Online]. Available: http: //www.proofcap.se

[15] K.-E. Leeb, D. Björklöf, and U. L. Lundgren, "Anordning med integrerad antenn för kapsling av radioelektronik samt sätt att tillverka anordningen," Swedish Patent SE0 201 263, 2003. 